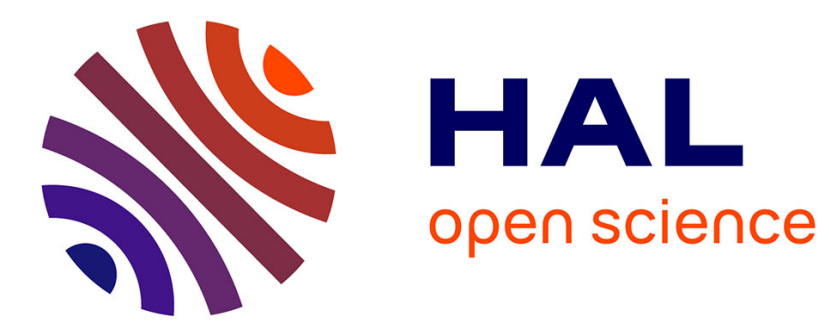

\title{
Freestanding-quality dislocation density in semipolar GaN epilayers grown on SOI: aspect ratio trapping
}

Rami Mantach, Philippe Vennéguès, Jesus Zúñiga-Pérez, Philippe de Mierry,

Marc Portail, Guy Feuillet

\section{- To cite this version:}

Rami Mantach, Philippe Vennéguès, Jesus Zúñiga-Pérez, Philippe de Mierry, Marc Portail, et al.. Freestanding-quality dislocation density in semipolar GaN epilayers grown on SOI: aspect ratio trapping. Applied Physics Express, 2020, 13 (11), pp.115504. 10.35848/1882-0786/abc1cd . hal03013787

\section{HAL Id: hal-03013787 \\ https://hal.science/hal-03013787}

Submitted on 3 Jan 2022

HAL is a multi-disciplinary open access archive for the deposit and dissemination of scientific research documents, whether they are published or not. The documents may come from teaching and research institutions in France or abroad, or from public or private research centers.
L'archive ouverte pluridisciplinaire HAL, est destinée au dépôt et à la diffusion de documents scientifiques de niveau recherche, publiés ou non, émanant des établissements d'enseignement et de recherche français ou étrangers, des laboratoires publics ou privés. 


\title{
Freestanding-quality dislocation density in semipolar GaN epilayers grown on SOI: aspect ratio trapping.
}

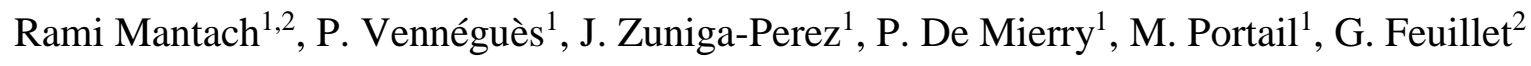 \\ ${ }^{1}$ CRHEA, CNRS, Université Côte d'Azur, rue Bernard Grégory 06560 Valbonne, France. \\ ${ }^{2}$ Université Grenoble Alpes, CEA LETI 17 rue des Martyrs 38054 Grenoble, France.
}

Email : guy.feuillet@cea.fr, pv@crhea.cnrs.fr

\begin{abstract}
We demonstrate that the Aspect Ratio Trapping technique, aimed at blocking threading dislocations and implemented for cubic materials, can also be used for hexagonal symmetry materials such as GaN. We used patterned (001) $6^{\circ}$ off Silicon On Insulator substrates to grow

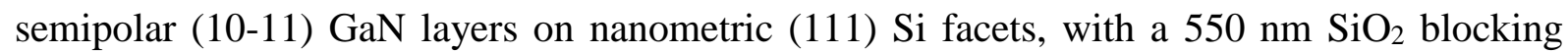
mask. The dislocations coming from the inclined growth facet are shown to bend in the c-plane and trapped on the sidewall of the mask. The semipolar GaN layers have dislocation densities smaller than $10^{7} / \mathrm{cm}^{2}$, mimicking the dislocation density of commercial c-oriented GaN freestanding substrates.
\end{abstract}

Most GaN-based optoelectronic devices are grown along the polar c-direction of the wurtzite structure. However, heterostructures grown along this orientation present strong polarization fields ${ }^{1)}$ that are known to affect the device performances ${ }^{2}$. One solution to reduce these fields consists in growing the quantum well structures along semipolar directions (that make an angle with the c-axis of the GaN structure). Moreover, semipolar orientations are envisaged for long wavelength emission, because of easier indium incorporation than in c-orientation. In this way, efficient green and yellow LEDs have been realized by homo-epitaxy on low defects density free-standing substrates ${ }^{3,4)}$. Nevertheless, these solutions are not widely used because homoepitaxial growth along these semipolar directions relies on the use of high price and small size substrates. On the other hand, planar heteroepitaxy of semipolar $\mathrm{GaN}$ on foreign substrates results, whatever the substrate, in a high density of basal stacking faults (BSFs) and threading dislocations ${ }^{5}$. The best solution for reducing the defect density in semipolar $\mathrm{GaN}$ is the selective growth on silicon ${ }^{6-8)}$ or sapphire ${ }^{9,10)}$ patterned substrates. In such cases, GaN grows on inclined facets that do not cover the entire substrate surface, thereby limiting the footprint on the substrates and, thus, reducing the number of dislocations created at the GaN/substrate interface. Indeed, for most of semipolar growth processes, the dislocations generated at the layer/substrate interface first thread along the c-direction, then bend in the basal c plane ${ }^{11)}$ and finally reach the surface, leading to surface area with high dislocation densities alternating with almost dislocation-free stripes ${ }^{12}$. Many methods were developed to reduce further the dislocation and BSF densities: (i) 3-step growth process of GaN on sapphire ${ }^{13)}$, (ii) deeply grooved patterned sapphire ${ }^{14)}$, (iii) $\mathrm{SiN}$ interlayer that blocks the dislocations coming from the growth facets ${ }^{8)}$ Erreur! Signet non défini. (iv) Ge doping to avoid the presence of $-c$ facets, which are responsible for BSFs formation ${ }^{15)}$. We recently demonstrated the growth of (10-11) GaN on a SOI substrate ${ }^{16)}$ with a very low dislocation density $\left(7 \times 10^{7} / \mathrm{cm}^{2}\right)$, thanks to the use of nanometric $\mathrm{Si}$ (111) nucleation facets. In this letter, we combine the growth of (10-11) GaN on thin SOI as described in Ref.16, with the aspect ratio trapping (ART) technique. 
This technique was found to reduce drastically the dislocation density of lattice mismatch cubic materials, like $\mathrm{Ge}^{17)}$, InP and $\mathrm{GaAs}^{18)}$ grown on (001) Si substrates. It consists in performing localized growth in the aperture of a thick $\mathrm{SiO}_{2}$ mask, allowing dislocations localized in the inclined $\{111\}$ planes of (001) oriented cubic materials to be blocked on the sidewall of the mask.

The ART is inefficient for hexagonal c-oriented nitride materials since dislocations are mainly aligned along the c-direction, i.e. perpendicular to the substrate surface. Therefore, they cannot be trapped on the sidewall of a thick mask. However, for semipolar orientations one can take advantage of the fact that dislocations bend into the c-plane that is now inclined, thus allowing their trapping on the mask.

The ART technique consists in depositing a thick $\mathrm{SiO}_{2}$ mask to block all the dislocations coming from the Si/III-Nitride interface.

As schematized in Fig.1a), there is a minimal mask thickness over which no dislocations can thread up to the surface. This value, denoted $\mathrm{X}_{\min }$, is directly related to the width $\mathrm{W}$ of the upper (1-101) facet and to the inclination angle $\theta$, equal to $62^{\circ}$ in our case.

$$
X_{\min }=W \cdot \tan \theta
$$

$\mathrm{W}$ is related to the width of the $\mathrm{Si}_{(111)}$ facet $\mathrm{F}$ by the geometric relation:

$$
W=\frac{F}{2 \cdot \sin \frac{\alpha}{2}}
$$

Where $\alpha$ in Fig.1a) is the angle between the two adjacent $\{1-101\}$ planes, $\alpha=56^{\circ}$.

The width of the facet F is governed by the thickness $\mathrm{H}$ of the top Si layer, which is also the etching depth:

$$
F=H / \sin \theta
$$

Combining these 3 equations, we obtain:

$$
X_{\text {min }}=\frac{H}{2 \cdot \cos \theta \cdot \sin \frac{\alpha}{2}}
$$

Taking $\mathrm{H}=150 \mathrm{~nm}$, the minimum $\mathrm{SiO}_{2}$ thickness $\mathrm{X}_{\min }$ to be used for effective ART is only $340 \mathrm{~nm}$. This is the great advantage of SOI over bulk Si ${ }^{8)}$ which has large facets F (currently 1$2 \mu \mathrm{m}$ ) and thus requires large $\mathrm{X}_{\min }$ (typically 3-4 $\mu \mathrm{m}$ ) which strongly complicate the etching process defining the nucleation facets.

The SOI substrate was made using the standard Smart-Cut technology and consists in a $6^{\circ}$ off $150 \mathrm{~nm}$ thick <001> Si device layer, sitting on a $300 \mathrm{~nm} \mathrm{SiO}{ }_{2}$ buried oxide, the Si base wafer being of nominal $<001>$ orientation. The SOI wafers were 8 inches in diameter and cut into 36x36 mm samples. First, a $550 \mathrm{~nm}$ thick $\mathrm{SiO}_{2}$ layer was deposited onto the $\mathrm{Si}$ surface by ion beam sputtering. Patterning was achieved by a combination of conventional photolithography using a mask of stripes (period $5 \mu \mathrm{m}$, openings $2.5 \mu \mathrm{m}$ ) and dry etching of $\mathrm{SiO}_{2}$. The sample was then etched with a $\mathrm{KOH}$ solution to reveal the $\{111\} \mathrm{Si}$ facets. Fig.1b) shows a cross sectional SEM image of the patterned substrate. Note that the thickness of the $\mathrm{SiO}_{2}$ mask (550 $\mathrm{nm}$ ) is beyond the $340 \mathrm{~nm}$ required for effective ART. 
The process was followed by the uniform deposition of $100 \mathrm{~nm}$ thick AIN using Metal Organic Vapor Phase Epitaxy (MOVPE) to avoid the direct interaction between Ga and Si leading to the undesired meltback etching ${ }^{19)}$. The final step consisted in the directional deposition of $\mathrm{SiO}_{2}$ by ion beam sputtering in order to cover the whole surface except the AlN-covered Si facet and avoid parasitic growth elsewhere.

GaN growth was subsequently performed by MOVPE, using trimethylgallium (TMGa) and ammonia $\left(\mathrm{NH}_{3}\right)$ as precursors. Growth was carried out in two steps: the first one corresponds to the formation of inverted pyramidal bands at $1100^{\circ} \mathrm{C}$ and 300 Torr, using a TMGa and $\mathrm{NH}_{3}$ flow rate of $51 \mu \mathrm{mol} / \mathrm{min}$ and $76 \mathrm{mmol} / \mathrm{min}$, respectively. The second one consists in promoting the growth in the c-direction, at $1160^{\circ} \mathrm{C}$ and 100 Torr, using a TMGa and $\mathrm{NH}_{3}$ flow rates of 60 $\mu \mathrm{mol} / \mathrm{min}$ and $58 \mathrm{mmol} / \mathrm{min}$, respectively. An additional step, at a standard growth rate for semipolar layers $\left(108 \mu \mathrm{mol} / \mathrm{min} \mathrm{TMGa}\right.$ and $\left.67 \mathrm{mmol} / \mathrm{min}^{\mathrm{N} H}, \mathrm{~T}=1160^{\circ}\right)$ was performed to accelerate the coalescence of the neighboring $\mathrm{GaN}$ bands obtained at the end of the second step.

Fig. 2 shows SEM images of the growing (10-11) epilayer at different stages: (a) at the end of step 2, i.e. after the pyramidal bands formation, (b) and (c) after complete coalescence, achieved after about $4 \mu \mathrm{m}$ growth. We notice the absence of parasitic polycrystalline GaN crystals on the mask, indicating a perfect selectivity of the nucleation from the c-facets. No cracks and no meltback etching were detected on the whole sample surface $\left(36 \times 36 \mathrm{~mm}^{2}\right)$.

Fig. 3 shows the $11 \mathrm{~K}$ photoluminescence spectra of a coalesced epilayer on ART-SOI (mask thickness $550 \mathrm{~nm}$ ) in comparison with a coalesced epilayer on standard SOI (mask thickness $50 \mathrm{~nm}$ ) described in Ref.16. The band edge peak is associated to the donor bound exciton $\mathrm{D}^{\circ} \mathrm{X}$. For the epilayer grown on ART-SOI (thick mask), $\mathrm{D}^{0} \mathrm{X}$ lies at $3.466 \mathrm{eV}$ compared to $3.470 \mathrm{eV}$ on standard SOI (thin mask). Given that the strain-free $\mathrm{D}^{0} \mathrm{X}$ peak is expected at $3.471 \mathrm{eV}^{20}$ ), the epilayer grown on standard SOI is actually strain-free while the ART layer sustains a low tensile stress level. The low stress level explains the absence of cracks in the $4 \mu \mathrm{m}$ thick (10-11) ART epilayers. Beside the broad yellow band (YB) at $2.2 \mathrm{eV}$ and blue band (BB) at $2.9 \mathrm{eV}$, often encountered in non-intentionally doped $\mathrm{GaN}^{21)}$, the other PL peaks at lower energy are assigned to the radiative emission from structural defects, namely the different types of basal stacking faults $\mathrm{I}_{1}$ at $3.40 \mathrm{eV}, \mathrm{I}_{2}$ at $3.32 \mathrm{eV}^{22)}$. E-type $\mathrm{BSFs}^{22)}$ and/or partial dislocations terminating the c-plane $\mathrm{SFs}^{23)}$ are associated with the $3.27 \mathrm{eV}$ emission.

As seen in Fig.3, the main defects in ART-SOI are found to be $\mathrm{I}_{1}$-type SF and E-type SF and/or partial dislocations, whereas in standard SOI, $\mathrm{I}_{1}$-type and $\mathrm{I}_{2}$-type $\mathrm{SFs}$ dominate. This difference in the nature of SFs between ART and standard SOI is yet not fully understood.

To characterize the dislocations and BSFs distribution, cathodoluminescence (CL) was performed at $300 \mathrm{~K}$ and also at $80 \mathrm{~K}$, since the luminescence of BSFs is inefficient at room temperature. In Fig.4a) bands have not yet coalesced and dislocations are extremely rare, while in Fig.4b) the layer is coalesced and emerging dislocations under the shape of dark spots aligned along the [1-210] direction are detected. Hence, most dislocations emerging at the surface are generated upon coalescence. The TEM image of Fig. 5 clearly shows that these dislocations lie in the coalescence boundaries. The average dislocation density is $8.10^{6} / \mathrm{cm}^{2}$. This number is about one order of magnitude lower than in the case of nanometric facets alone, i.e. with no $\mathrm{ART}^{16)}$. Most importantly, this value is of the same order as that of commercial c-plane freestanding GaN substrates. Fig.4c) displays the CL contrast of the surface at $80 \mathrm{~K}$. Bright vertical lines correspond to BSFs emission. This image shows that the BSFs are present principally near the coalescence boundaries. The TEM analysis below will show that in this region the crystal has overgrown the $\mathrm{SiO}_{2}$ mask along the $-\mathrm{c}$ direction. The stripe area between the coalescence boundaries ( $+\mathrm{c}$ region) are mostly free of BSFs, although a stripe in the middle 
of Fig4c) exhibits several bright lines. The existence of these additional BSFs could be due to the low growth rate which is known to favor the incorporation of impurities and hence the formation of $\mathrm{BSFs}^{24)}$.

Cross-sectional scanning transmission electron microscopy (STEM) images have been recorded to evidence the dislocation blocking phenomenon. The zone axis for the cross section is along the [1-210] stripe direction. A small tilt from that zone axis allows distinguishing dislocations and BSFs: dislocations keep a linear contrast whereas BSF exhibit fringe contrast. Fig. 5a) clearly shows that dislocations are created at the Si /AIN interface, progressively bending into the inclined c plane of the pyramids. As expected, all of these bent dislocations end up on the sidewall of the thick $\mathrm{SiO}_{2}$ mask. Some BSFs, visible on the upper right hand side of the image, correspond to the usually observed stacking faults when growth occurs in the $-\mathrm{c}$ direction $^{12)}$. Moreover, one can also note the presence of extra BSFs in the $+c$-grown regions, which we believe are due to the low growth rate which is known to favor the incorporation of impurities and hence the formation of $\mathrm{BSFs}^{24)}$. The BSFs created in both the $-\mathrm{c}$ and $+\mathrm{c}$ - grown regions are also observed in the $80 \mathrm{~K} \mathrm{CL}$ image of Fig.4c). The total density of BSFs is estimated to be in the high $10^{4} \mathrm{~cm}^{-1}$ and, therefore, higher than in the standard SOI process (high $10^{3} \mathrm{~cm}^{-1}$ ). Fig. 5b) shows a cross sectional STEM image of an overall growth area including the coalescence zone, where dislocations appear due to the coalescence of stripes. This observation corroborates the CL image in Fig.4b), indicating that the only observed dislocations originate from the coalescence of the bands. Indeed, neighboring bands may be slightly misoriented with respect to each other leading, upon coalescence, to the formation of sub-grain boundaries in between them and to the presence of these residual and highly localized dislocations.

In this letter we have shown the usefulness of the aspect ratio technique (ART) in order to systematically reduce the dislocation density in semipolar (10-11) GaN layer grown on a silicon platform (patterned SOI substrates). A comparison between layers grown on ART SOI substrates with those grown on standard SOI substrates reveals that we could reduce the dislocation density by a factor of about 10, thus mimicking the dislocation density of commercial $c$-oriented $\mathrm{GaN}$ freestanding substrates. As revealed by CL, dislocation densities in the high $10^{6} / \mathrm{cm}^{2}$ have been reached, establishing, to our knowledge, the state of the art for the dislocation density in heteroepitaxial semipolar nitrides. TEM images reveal that the dislocation blocking mechanism is indeed at play on the sidewall of the $\mathrm{SiO}_{2}$ mask, while the remaining dislocations are found to be localized at the coalescence boundary between adjacent bands. One now has the possibility to take full advantage of the semipolar orientations, namely for the development of longer wavelength emitters. On the other hand, stacking faults have been detected in the - c-grown regions as expected but also randomly distributed in the $+c-$ grown regions for a total density in the high $10^{4} \mathrm{~cm}^{-1}$. These stacking faults being due to the low growth rate used in these studies, fine adjustment of the growth rate and morphology, e.g. by exploiting Ge as n-dopant ${ }^{15}$, should allow reducing the density of these defects which are known to be detrimental to the optical efficiency of LEDs. Thus, overall we have now the opportunity, by combining different approaches, to provide a high-quality heteroepitaxial semipolar GaN development for further device development.

\section{Acknowledgments}

The authors thank IMRA Europe S.A. for the access to the JEOL 2100 transmission electron microscope. R. M. acknowledges support through GANEX funding (ANR-11-LABX-0014) for his $\mathrm{PhD}$. 


\section{References}

1) F. Bernardini, V. Fiorentini, and D. Vanderbilt, Phys. Rev. B 56, R10024 (1997).

2) P. Waltereit, O. Brandt, A. Trampert, H. T. Grahn, J. Menniger, M. Ramsteiner, M. Reiche, and K. H. Ploog, Nature 406, 865 (2000).

3) S. Yamamoto, Y. Zhao, C. C. Pan, B. R. Chung, K. Fujito, J. Sonoda, S. P. DenBaars and S. Nakamura, Appl. Phys. Express 3, 122102 (2010).

4) H. Masui, S. Nakamura, S.P. DenBaars, and K. Mishra, IEEE Trans. Electron Devices, 57, 88 (2010).

5) P. Vennéguès, Z. Bougrioua, and T. Gühne, Jpn. J. Appl. Phys. 46, 4089 (2007).

6) Y. Honda, N. Kameshiro, M. Yamaguchi, and N. Sawaki, J. Cryst. Growth 242, 82 (2002).

7) T. Hikosaka, T. Narita, Y. Honda, M. Yamaguchi and N. Sawaki, Appl. Phys. Lett. 84, 4717 (2004).

8) M. Khoury, P. Vennéguès, M. Leroux, V. Delaye, G. Feuillet and J. Zuniga-Perez, J. Phys. D : Appl. Phys. 49, 475104 (2016).

9) S. Schwaiger, I. Argut, T. Wunderer, R. Rösch, F. Lipski, J. Biskupek, U. Kaiser and F. Scholz, Appl. Phys.Lett. 96, 231905 (2010).

10) N. Okada, A. Kurisu, K. Murakawi and K. Tadatomo, Appl.Phys. Exp. 2, 091001 (2009).

11)P.Vennéguès, B.Beaumont, V. Bousquet, M. Vaille and P. Gibart, J. Appl. Phys. 87, 4175 (2000).

12)P. Vennéguès, Semicond. Sci. Technol. 27, 024004 (2012).

13) F. Tendille, P. De Mierry, P. Vennéguès, S. Chenot and M. Teisseire, J. Cryst. Growth 404, 177 (2014).

14) F. Tendille, D. Martin, P. Vennéguès, N. Grandjean and P. De Mierry, Appl. Phys. Lett. 109, 082101 (2016).

15) J. Song Choi, C. Zhang, Z. Deng, Y. Xie and J. Han , ACS Appl. Mater. Interfaces 11, 33140 (2019). 
16) R. Mantach, P. Vennéguès, J. Zuniga-Perez, P. De Mierry, M. Leroux, M. Portail and G. Feuillet, J. Appl. Phys. 125, 035703 (2019).

17) J.S. Park, J. Bai, M. Curtin, B. Adekore, M. Carroll and A. Lochtefeld, Appl. Phys. Lett. 90, 052113 (2007).

18) J. G. Fiorenza, J.S. Park, J. Hydrick, J. Li, J. Li, M. Curtin, M. Carroll, and A. Lochtefeld, ECS Transactions, 33 (6), 963 (2010).

19) M. Khoury, O. Tottereau, G. Feuillet, P. Vennéguès and J. Zúñiga-Pérez, J. Appl. Phys. 122, 105108 (2017).

20) P. P. Paskov, B. Monemar, A. Toropov, J. P. Bergman, and A. Usui, Phys. Stat. Sol. (c) 4, 2601 (2007).

21) M. A. Reshchikov and H. Morkoç, J; Appl. Phys. 97, 061301 (2005).

22) J. Lähnemann, O. Brandt, U. Jahn, C. Pfüller, C. Roder, P. Dogan, F. Grosse, A. Belabbes, F. Bechstedt, A. Trampert, and L. Geelhaar, Phys. Rev. B 86, 081302 (2012).

23) R. Liu, A. Bell, F. A. Ponce, C. Q. Chen, J. W. Yang, and M. A. Khan. Appl. Phys. Lett. 86, 021908 (2005).

24) Y.J. Sun, O. Brandt, U. Jahn, T. Y. Liu, A. Trampert, S. Cronenberg, S. Dhar and K. H. Ploog, J. Appl. Phys. 92, 5714 (2002). 


\section{Figure Captions}

Fig. 1. (a) Schematic representation of dislocation blocking when using the ART technique on a SOI substrate; (b) cross sectional SEM image of the patterned SOI-ART .substrate.

Fig.2: a) Bird-eye view SEM image of the GaN stripes grown on SOI-ART before coalescence, b) cross sectional SEM image of a fully-coalesced GaN layer on SOI-ART c) Bird-eye view SEM image of a coalesced layer.

Fig. 3: Low temperature photoluminescence of two (1-101) GaN epilayers grown on standard SOI $\left(50 \mathrm{~nm} \mathrm{SiO}_{2}\right)$ and on ART SOI $\left(550 \mathrm{~nm} \mathrm{SiO}_{2}\right)$.

Fig. 4: 300K CL image of a) non coalesced GaN stripes (dark zones indicated by red marks correspond to empty space between $\mathrm{GaN}$ stripes), and b) coalesced layer, c) $80 \mathrm{~K} \mathrm{CL}$ panchromatic image of a coalesced GaN layer. The arrows indicate the location of the coalescence boundaries.

Fig. 5: (a): STEM cross sectional bright field image of the GaN layer along the [1-210] zone axis. Dislocations generated at the AlN on Si interface are blocked by the thick $\mathrm{SiO}_{2}$ mask. BSFs are observed in the -c-grown region and rarely in the +c-grown region; (b) STEM annular dark field cross sectional image along the [1-210] zone axis of a full period of the patterned structure. This image shows BSFs in the -c-grown regions, a few extra SFs created randomly in the GaN stripes and dislocations in coalescence boundaries. 


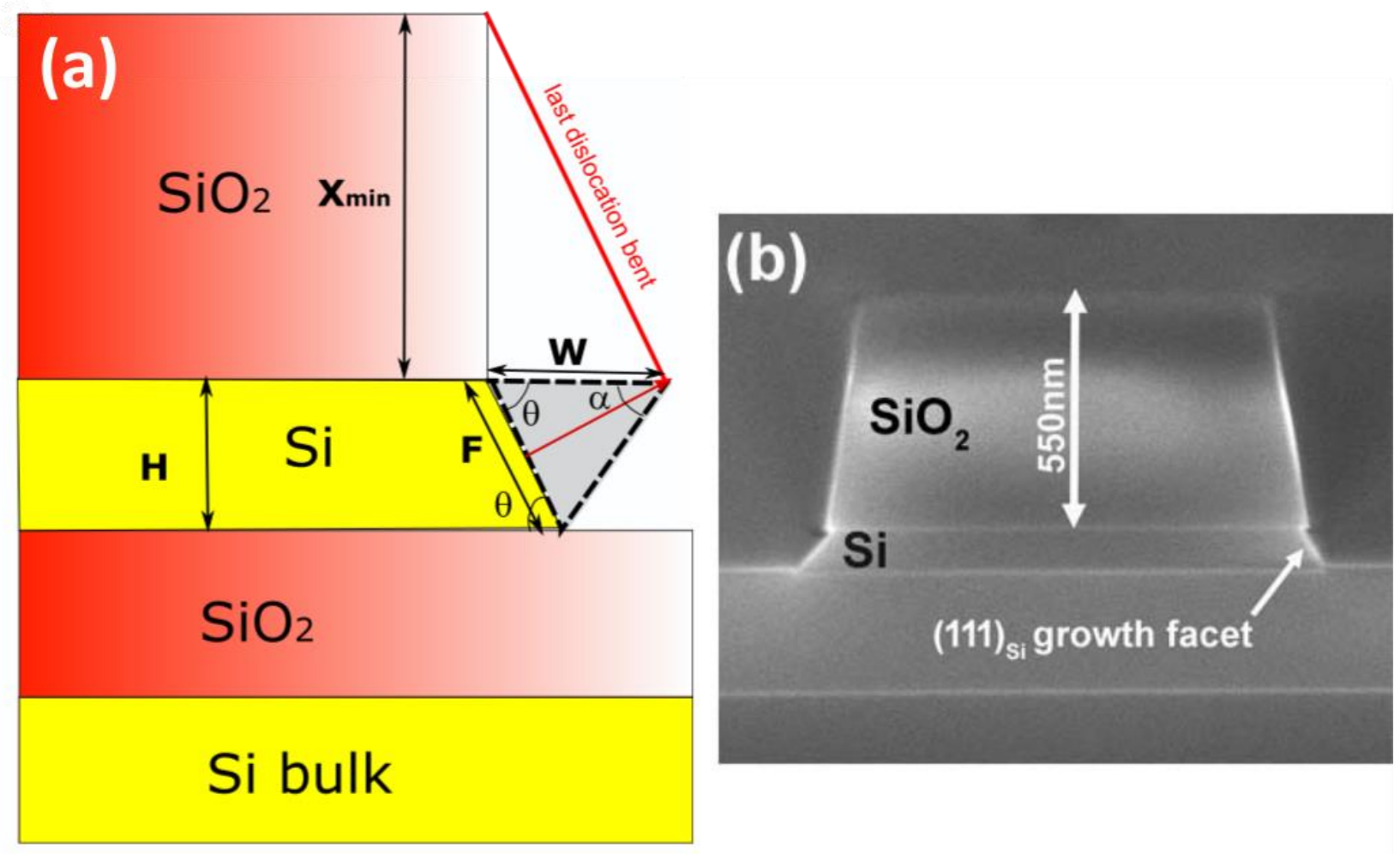

Fig.1. 


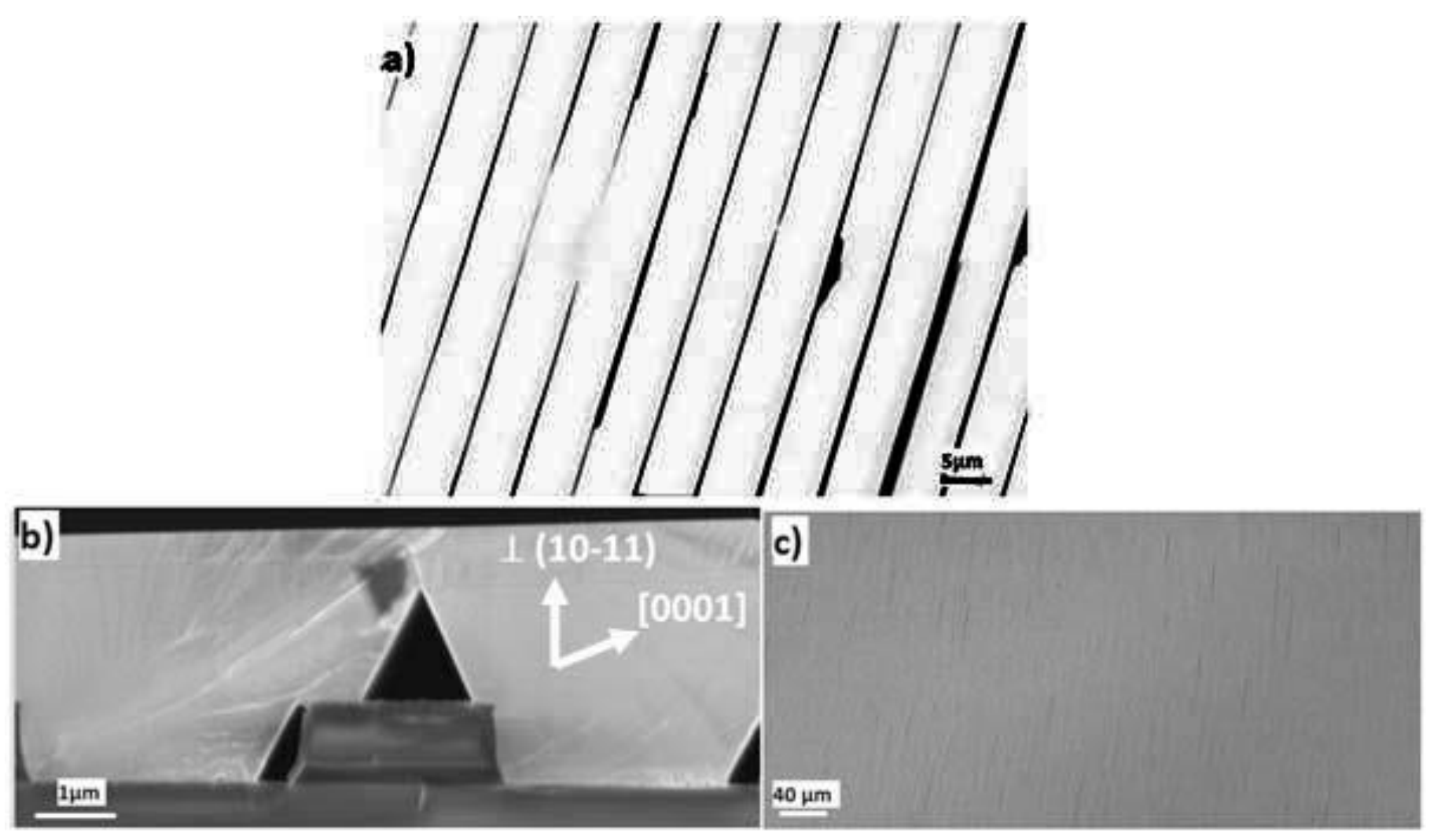

Fig.2. 


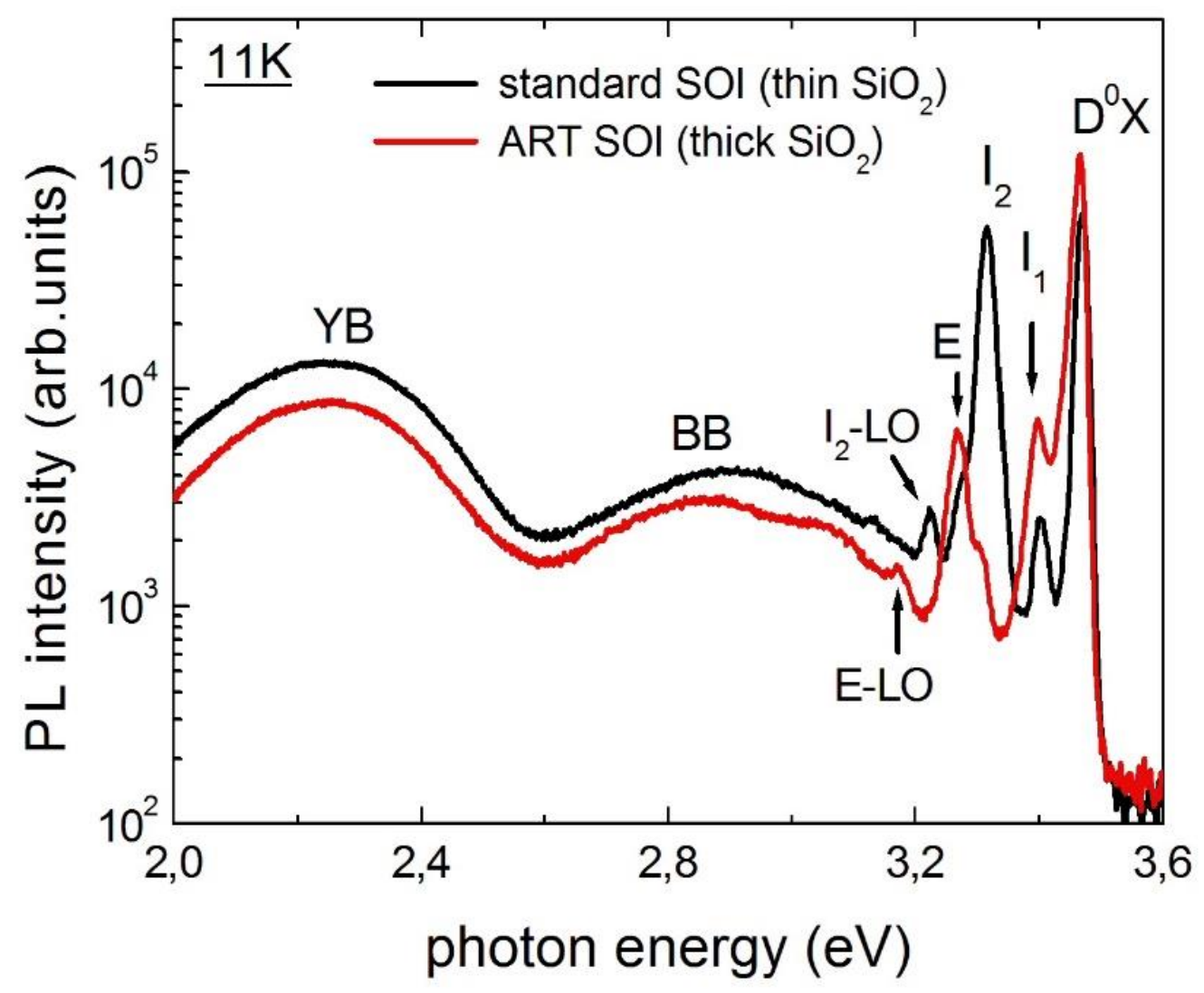

Fig.3. 


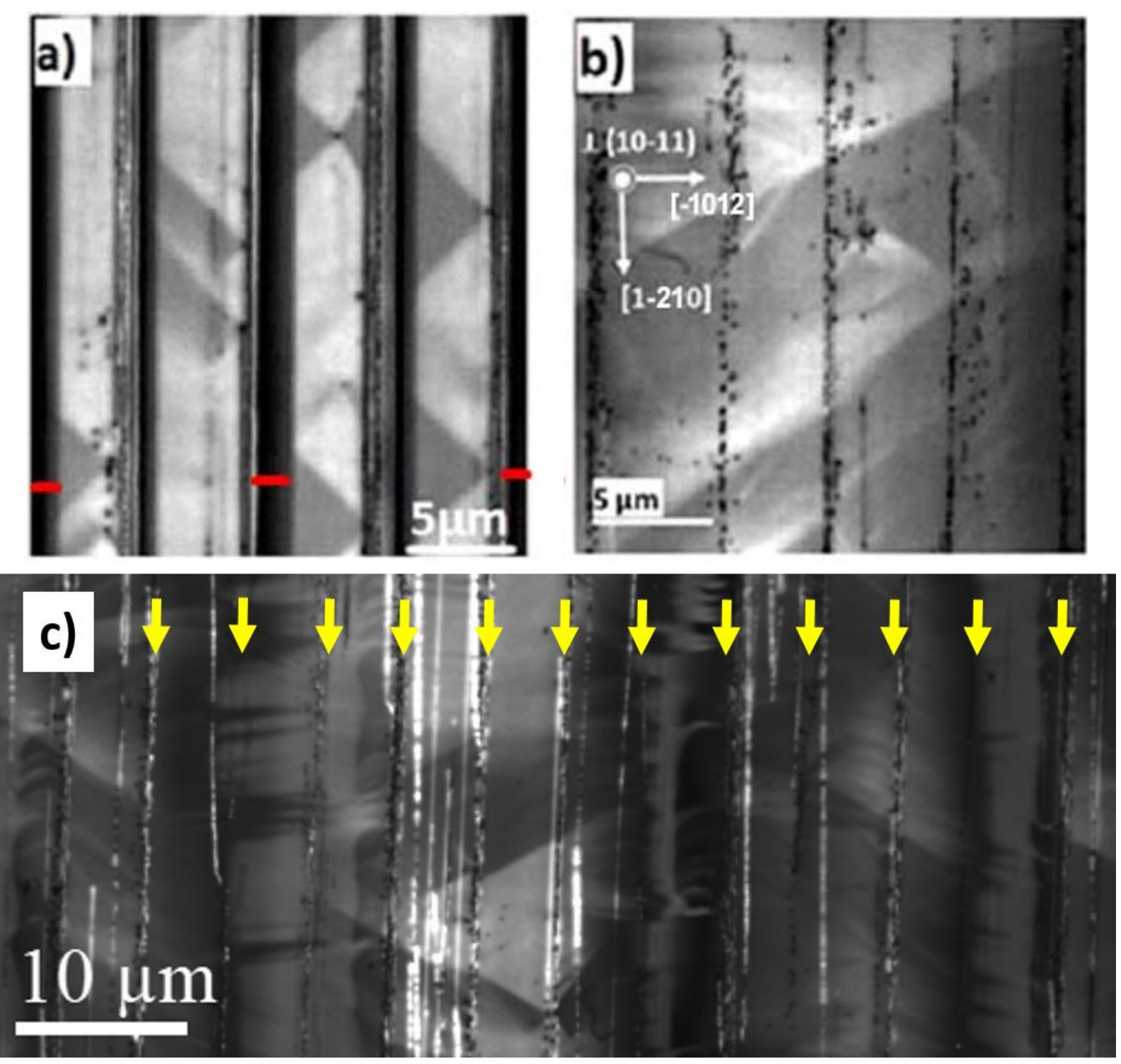

Fig.4. 


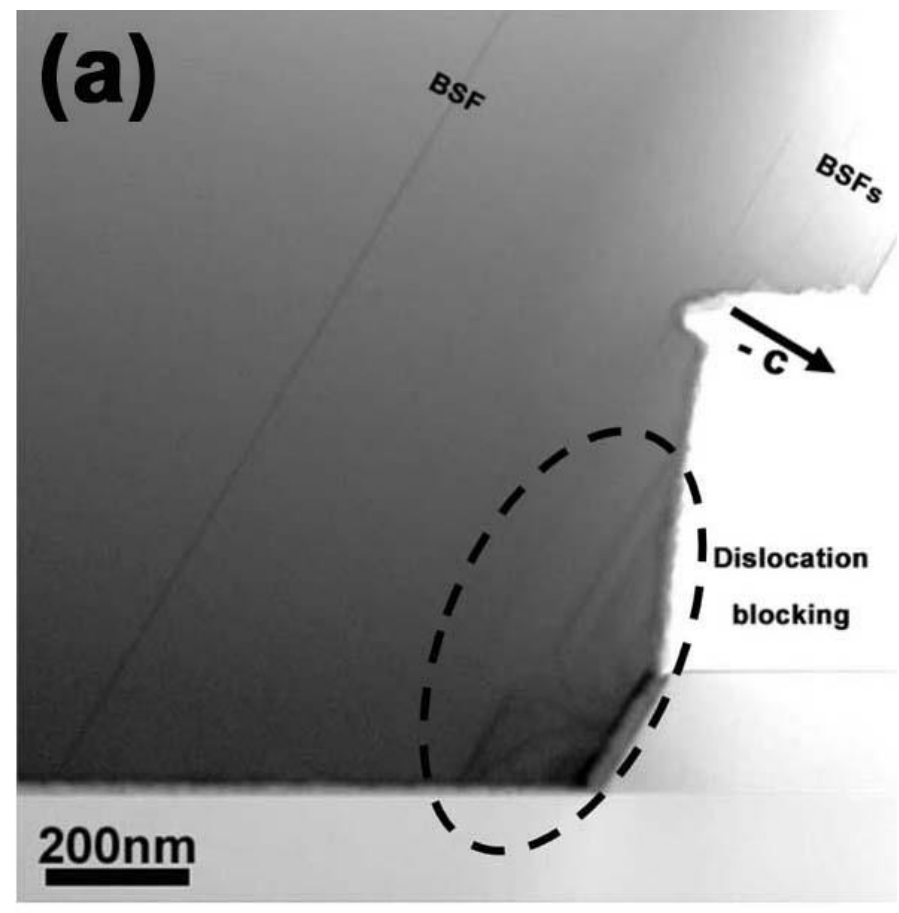

Dislocations from coalescence

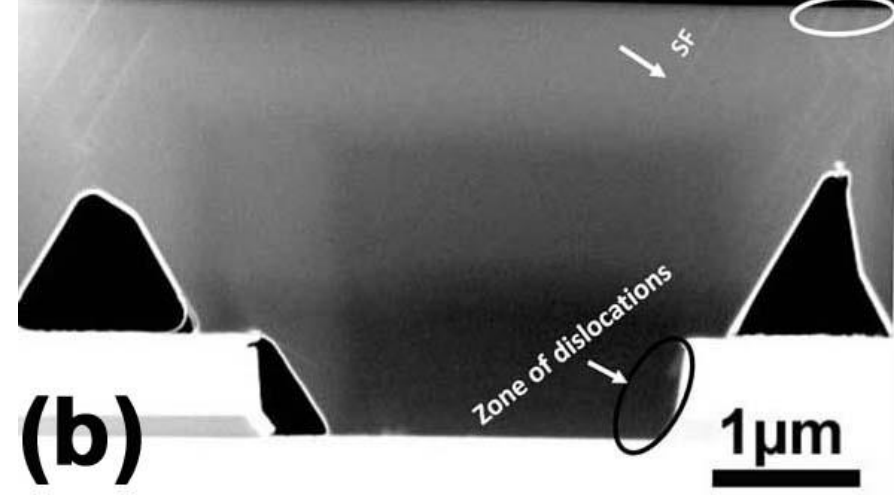

Fig.5. 